\title{
O estudo de casos múltiplos: estratégia de pesquisa em psicanálise e educação
}

\author{
Cristiana Carneiro* \\ Universidade Federal do Rio de Janeiro, Faculdade de Educação. Rio de Janeiro, RJ, Brasil
}

\begin{abstract}
Resumo: 0 estudo de casos será discutido como metodologia de pesquisa na articulação entre psicanálise e educação. Tal discussão se insere no trabalho efetuado pela parceria entre o Núcleo Interdisciplinar de Pesquisa e Intercâmbio para a Infância e Adolescência Contemporâneas da Universidade Federal do Rio de Janeiro (Nipiac-UFRJ), o Instituto de Psiquiatria (UFRJ), a Faculdade de Educação da UFRJ e da Universidade Federal Fluminense (UFF), onde casos de crianças e adolescentes com entraves na escolarização foram objeto de análise. Pela temática do mal-estar na escolarização, o estudo de casos aliado à pesquisa-intervenção se ofereceu propício para a análise de fenômenos contemporâneos inseridos em contextos de vida real. Discute-se aqui sobre a importância da definição dos casos, da questão de estudo e produção do material, sua organização e análise, bem como possíveis resultados e produtos. Por fim, é tecida uma reflexão sobre os desafios metodológicos encontrados na realização da pesquisa.
\end{abstract}

Palavras-chave: estudos de caso, metodologia de pesquisa, psicanálise, educação.

\section{O estudo de caso como estratégia de pesquisa}

Segundo Ventura (2007), não há consenso sobre a origem da utilização do estudo de caso como estratégia de pesquisa. Três direções são oferecidas prioritariamente por diferentes autores: (1) uma que aponta a psicologia e medicina como precursoras; (2) outra a partir dos estudos antropológicos de Malinowski e da Escola de Chicago (Chizzotti, n.d. citado por Ventura, 2007, p. 384); e (3) a que aponta os estudos jurídicos de Laugdell (Gil, n.d. citado por Ventura, 2007, p. 384). De acordo com Yin (2005, p. 32), o estudo de caso "é uma investigação empírica que investiga um fenômeno contemporâneo dentro de seu contexto de vida real, especialmente quando os limites entre o fenômeno e o contexto não estão claramente definidos".

Estudar fenômenos contemporâneos em contrapartida a históricos exige muitas vezes do pesquisador um olhar e participação no próprio contexto onde o fenômeno vem acontecendo. Fatos da vida real, vividos em seu contexto, não são passíveis de inserção em ambientes controlados e tampouco nos asseguram um vetor predominante de previsibilidade. Nesse sentido o estudo de caso visa compreender fenômenos sociais e psicológicos complexos, em que múltiplas variáveis intervêm. É nessa direção que elegemos essa estratégia como possibilidade de incrementar o debate entre a psicanálise e a educação nos assuntos que envolvem infância e adolescência. Mais particularmente, por meio do estudo do mal-estar na escolarização. Para efeito da pesquisa o termo mal-estar foi tomado, inicialmente, da forma mais abrangente possível, justamente para que, a partir dos casos, ele fosse descrito e analisado em

* Endereço para correspondência: cristianacarneiro13@gmail.com profundidade em cada situação específica. Teceu-se, dessa forma, um caminho que foi do mais geral ao particular, tendo a queixa como ponto de partida. Nesse sentido, em princípio, entendeu-se mal-estar na escolarização como uma ampla gama de dificuldades que envolvem a criança e adolescente com o ambiente escolar. Inserem-se aí: problemas de aprendizagem, dificuldades em relacionamentos entre pares na escola, dificuldades na relação professor-aluno, questões que envolvam leitura e escrita, agressividade e atenção, enfim, tudo aquilo que pode ser descrito como causador de mal-estar na relação da criança ou adolescente com a escola, ou com o entorno (a família, por exemplo) a partir das questões escolares. Paín (1985, p. 13) enfatiza uma diferença entre problemas de aprendizagem e problemas escolares, estes últimos mais abrangentes, envolvendo indisciplina e integração, podendo ser uma formação reativa diante de uma transição difícil do grupo familiar ao grupo social. No entanto, não utilizamos o termo problema, já que este pressupõe a formulação de uma situação conflitiva e de entraves já com algum nível de enunciado. Ou seja, se problema reenvia a um contexto já com alguma definição, mal-estar reenvia para algo mais difuso, remetido justamente ao encontro do pulsional com a cultura (Freud, 1930/1996d). O alargamento do termo assim definido interessa justamente porque possibilita uma abertura maior de sentidos possíveis para aquilo que inicialmente apareceu como queixa. O mal-estar pode ser anunciado pela própria criança, bem como pela escola em relação à criança ou adolescente, pela família ou ainda por algum especialista cuidador dessa criança ou adolescente. Destarte a queixa de malestar na escolarização é a prerrogativa para o estudo de casos, ainda que ela seja enunciada por diferentes fontes. Uma criança pode, por exemplo, não apresentar nenhum problema de rendimento escolar, não tendo sido 
apontados problemas de aprendizagem, no entanto, ao apresentar comportamento continuamente irrequieto, causar mal-estar no grupo, o que reverterá para ações que envolvem diretamente a vida da criança/adolescente na escola. Outra prerrogativa é que a criança/adolescente estivesse sendo atendida no Instituto de Psiquiatria da UFRJ (Ipub-UFRJ), portanto, que a Psiquiatria tenha sido convocada a tratá-la. Isso faz parte do próprio solo de onde partiu a iniciativa de estudar casos, já que em 2011 a Direção do Serviço de Psiquiatria da Infância e Adolescência (Spia) do Ipub fez contato conosco, o Núcleo Interdisciplinar de Estudos e Pesquisas para a Infância e Adolescência Contemporâneas (Nipiac) e as Faculdades de Educação da Universidade Federal do Rio de Janeiro e da Universidade Federal Fluminense (FE-UFRJ/UFF). ${ }^{1}$ $\mathrm{O}$ intuito do contato partiu da inquietação em relação à quantidade de queixas referentes à escola no universo de crianças e adolescentes encaminhados para o serviço e o pouco ou nenhum desdobramento mais constante em relação ao tema. Ou seja, a única ponte mais concreta entre o usuário e a escola ocorria por meio do medicamento e, em alguns casos, relatório da escola.

O interesse na ampliação do olhar médico coadunou-se ao exercício da interdisciplinaridade que o Nipiac vem desenvolvendo, resultando em um propósito de articulação entre diferentes institutos no âmbito da UFRJ (Ipub, FE e IP) e da UFF (FE). Em vez de uma criança/adolescente fragmentada entre os especialismos, buscou-se uma integração das ações e reflexões dos diferentes profissionais envolvidos bem como, necessariamente, a participação da própria criança/ adolescente e família no processo. Nesse sentido, o estudo de casos se articula à pesquisa-intervenção inserida no modelo qualitativo nos termos propostos por Bauer e Gaskell (2002), concentrando-se na relação sujeito/objeto que parte do observador, dentro de um contexto, e pergunta como os acontecimentos se relacionam às pessoas que os experienciam. Trata-se, ainda, de uma pesquisa inserida no paradigma de construção de subjetividades. A pesquisa de construção de subjetividades se volta para o processo, para os modos de subjetivação, e não para o sujeito em si, como se este fosse já dado ou constituído. Nesse sentido, a pesquisa de produção de subjetividades refere-se a uma construção pensada como gestada no tecido social: "isso não quer dizer que devemos ignorar a existência de uma individuação das subjetividades - afinal, não se trata de negar a existência do sujeito, mas afirmá-lo como uma forma provisória, prismática e avessa à idéia de totalização" (Catharino, 2001, p. 46).

Os encontros com crianças e adolescentes, família e escola situaram-se dentro de um modelo de pesquisaintervenção, no qual se pretendeu ao mesmo tempo investigar e viabilizar a construção de um espaço de fala

1 Integra-se a esse contexto a pesquisa Infância, adolescência e malestar na escolarização: Estudo de casos em Psicanálise e Educação, coordenada pela autora deste artigo juntamente à professora doutora Luciana Gageiro Coutinho (PPGE-UFF). e intercâmbio entre eles e os pesquisadores. Esse modelo tem inspiração teórica, em sua origem, nas metodologias participativas e na pesquisa-ação oriundas das ciências sociais que desconstroem o mito da objetividade, posto que o objeto estudado é modificado pelo campo de pesquisa. Da mesma forma, também busca como inspiração teórica uma abordagem clínica sustentada pelos pressupostos da psicanálise, utilizados fora de seu dispositivo de intervenção tradicional (Castro \& Besset, 2008).

\section{Definição do caso}

Ainda que no estudo de caso clássico, um "caso" possa ser um indivíduo (Yin, 2005, p. 43) esta unidade de análise per se não é suficiente. Um caso é sempre um recorte da realidade e, ainda que seja uma pessoa, será um aspecto específico ou conjunto de características que a tornarão um caso a pesquisar. Nesse sentido, definir o que se constituirá num caso não é tarefa fácil. Em nossa pesquisa, ainda que tivéssemos três pré-requisitos fundamentais para a escolha dos casos (ser criança ou adolescente, ser atendido pela psiquiatria e apresentar alguma queixa de mal-estar na escolarização), o aprofundamento dos critérios de escolha se fez importante no sentido de tornar mais relevante a relação entre o que se pretendeu pesquisar e o universo pesquisado. Neste sentido, efetuamos uma pesquisa piloto, de caráter exploratório, durante o primeiro semestre de 2012 a fim de compreender melhor o campo. Este estudo concentrou-se numa análise documental, a partir da leitura de 285 fichas de triagem (total de crianças e adolescentes que procuraram o serviço no primeiro semestre de 2012). Os questionamentos principais podem ser assim descritos: quantas crianças e adolescentes procuraram o serviço? Destas, quantas apresentaram queixas referidas à escola? Quais foram as principais queixas? O intuito do mapeamento era compreender melhor o grupo de crianças e adolescentes que procuram o SPIA de maneira mais geral, para então selecionar casos que, em sua particularidade, pudessem de alguma forma contribuir para uma reflexão estendida desse universo (Carneiro \& Coutinho, 2015). Duas queixas se configuraram como prevalentes neste levantamento (dificuldade de aprendizagem-agitação), um recorte dentro do que chamamos mal-estar na escolarização, e se configuraram como critérios de escolha dos casos. Os cinco casos escolhidos pretenderam representar, de certa forma então, o grande grupo encaminhado com estas duas queixas prevalentes (dificuldade de aprendizagemagitação) numa expectativa de que pudessem trazer mais elementos sobre a maior parte dos encaminhamentos ao serviço.

Segundo Verztman (2013, p. 71), "um estudo de caso é, portanto, um método naturalístico e é uma forma de estudo que visa a descrição e a compreensão do singular" acreditando que este possa contribuir para 
a compreensão de uma realidade maior. Neste sentido buscamos o caso representativo, ou seja, aquele que supostamente representará melhor o universo de interesse, como nos diz Yin (2005, p. 63): "Parte-se do princípio de que as lições que se aprendem desses casos fornecem muitas informações sobre as experiências da pessoa ou instituição usual". No entanto, ainda que este seja um princípio norteador metodológico, ao utilizarmos a psicanálise como teoria de referência, sabemos que a singularidade terá sempre um lugar de destaque na compreensão do caso. Num sentido diferente do modelo médico para o qual "o caso remete ao sujeito anônimo que é representativo de uma doença ...) para nós, ao contrário, o caso exprime a própria singularidade do ser que sofre e da fala que ele nos dirige" (Nasio, 2001, p. 11). Outro ponto importante foi a escolha de casos múltiplos e não únicos em nossa pesquisa. Justamente por usar a teoria psicanalítica num contexto estendido, ou melhor, por não se tratar de um contexto clínico clássico, acreditamos que mais casos forneceriam mais situações comparativas de análise contribuindo, assim, para incrementar a confiabilidade na triangulação do material produzido. Em nossa pesquisa inicial, especificamente, incluímos sete crianças e adolescentes atendidos no Spia que apresentassem como motivos de entrada no serviço problemas de escolarização vinculados a queixas de dificuldade de aprendizagem e agitação. Resumindo, nossa pesquisa definiu os seguintes critérios de elegibilidade dos casos: ser criança/adolescente, estar sendo atendido no SPIA, apresentar queixa de mal-estar na escolarização - especificamente dificuldade de aprendizagem e/ou agitação. Essas características comuns definiram a escolha dos casos. Como diz Verztman (2013, p. 69), "nas ciências humanas um caso é um aspecto da realidade que será investigado e que deve ter certas características regulares".

Ao início da pesquisa, seguindo esses critérios, escolhemos cinco crianças e dois adolescentes. Ao longo e final da pesquisa ficamos com três crianças e dois adolescentes, pois uma criança foi encaminhada para atendimento externo à instituição e outra encaminhada para outro serviço na própria instituição. Esta última teve o encaminhamento com a participação do projeto, no entanto sua permanência diminuída na pesquisa gerou um quantitativo de material do caso muito inferior a todos os outros e a equipe decidiu não utilizá-lo para análise. A escolha dos oito casos iniciais também levou em conta a possibilidade de execução da proposta (pesquisadores disponíveis para sistematicamente ir à escola, entrevistadores, reunião com familiares).

\section{Casos múltiplos?}

A escolha de mais de um caso, como já apontado, não visou a replicação, mas a possibilidade comparativa. Assim, estudar os cinco casos e trabalhar os discursos possibilitou criar linhas de convergência e divergência sobre o material. Não pretendíamos avaliar a incidência dos fenômenos, mas justamente lançar luz sobre o contexto no qual ele se produziu. Assim, segundo Yin (2005), nosso estudo de casos foi do tipo explanatório visando responder como e porque o mal-estar se produziu naquelas situações. Mas, como nos diz Verztman (2013), comparar casos é motivo de grandes questões e controvérsias na literatura psicanalítica. A singularidade e as diferenças de contexto são tão importantes que apontam, não raro, para o incomparável. No entanto, nos adverte o autor que "comparar modelos, abstrações que servem para dar alguns parâmetros à nossa prática, não é o mesmo que comparar sujeitos" (Verztman, 2013, p. 75, grifos do autor) e, ainda, que não devemos recuar diante da dificuldade.

O elemento comparativo de análise foi o mal-estar e como, longitudinalmente ao longo de dois anos, ele foi se deslocando da queixa inicial para um discurso mais nítido e implicado dos agentes que o enunciaram. Esse aspecto mais interventivo da pesquisa foi discutido no texto Infância, adolescência e mal-estar na escolarização: interlocuções entre a psicanálise e a educação (Carneiro $\&$ Coutinho, 2016). De outra forma, quanto à própria descrição e nomeação do mal-estar, ela foi comparada nos diferentes casos a partir dos quatro grandes eixos de análise: família, escola, sujeitos e especialistas. Nesse sentido, por exemplo, como o discurso das diferentes escolas nomeou o mal-estar em relação aos casos, tornou-se um subeixo comparativo. Também o discurso dos familiares sobre o mal-estar criou um grande repertório de material em que foram buscadas temáticas prevalentes, afastamentos, recorrências e relações específicas com os casos e entre eles.

\section{Questão do estudo e produção do material}

Ao elegermos como ponto teórico de interesse o termo mal-estar (Freud,1930/1996d), o fazemos no sentido de concordar que a construção da civilização impõe uma série de restrições ao pulsional e que, com isso, estar na e produzir cultura, longe de ser um processo harmonioso, configura-se num processo conflitivo, de permanente tentativa de equilíbrio. Como diz Millot (2001, p. 109), relendo o texto freudiano: "será possível encontrar um equilíbrio entre as reivindicações do indivíduo e as exigências culturais?". A partir da psicanálise, esse equilíbrio será sempre provisório e trabalhoso, o que caracteriza o mal-estar como condição da própria cultura, indo num sentido contrário do binarismo bem-estar/malestar. A instituição escola, enquanto agente importante do processo civilizatório, não estaria isenta dos aspectos conflitivos que envolvem a relação do indivíduo com a cultura, com seus semelhantes e consigo próprio. No entanto, "a educação revela ser 'funesta' quando mantém o desconhecimento dos desejos e dos conflitos entre estes" (Millot, 2001, p. 115). Isso quer dizer que, quando a educação se faz num vetor prioritariamente alienante, de 
assujeitamento, em que a divisão subjetiva não é levada em conta, concorre-se para o aumento do mal-estar e suas consequências. A atenuação do mal-estar, indo num sentido contrário, poderia passar pelo reconhecimento desse real de discórdia que nossos desejos constituem (Millot, 2001), no sentido do que Freud postulou como educação para a realidade (Freud, 1927/1996c). Isso aponta para uma possibilidade elaborativa do mal-estar, um saber fazer com ele, o que caminharia em sentido diferente de uma tentativa de o erradicar, num discurso que acredita numa sociedade do bem-estar. Portanto incluir o malestar e a partir dele construir seria parte de uma educação norteada pela realidade da castração. Nesse sentido, o objetivo do estudo de casos ora apresentado foi ampliar a discussão sobre dificuldades na escolarização de crianças e adolescentes visando integrar vários discursos, mais especificamente, a família, a escola, especialistas e a própria criança e o adolescente.

As inúmeras dificuldades que se apresentam na educação de crianças e adolescentes hoje nos levam a pensar e questionar o modo como estas são tratadas teoricamente. É bastante comum a queixa dos educadores sobre o "fracasso" de seus alunos que é identificado muito comumente como expressão de um sintoma individual (TDAH, dislexia, déficits cognitivos etc.) da criança/ adolescente, o que é corroborado no âmbito médico e/ ou psicológico pela tendência atual à medicalização, mas muito raramente leva-se em conta a singularidade dos sujeitos e a situação em que se apresentam os problemas. Os textos psicanalíticos (Bergès, 1999; Jerusalinsky, 1999; Mannoni, 1999; Colli \& Kupfer, 2005; Santiago, 2005; Lajonquière, 2010) chamam atenção para o fato de que o discurso médico-pedagógico sobre as dificuldades de aprendizagem e de escolarização muitas vezes não leva em conta as particularidades do sujeito e de seu contexto. Ao tratar a questão de forma isolada, descontextualizada e descritiva, a dimensão singular daquela manifestação sintomática para aquele sujeito é perdida, juntamente com a possibilidade de que ele se implique na investigação e no tratamento de sua dificuldade. Partiu-se do pressuposto de que ampliar a discussão sobre as dificuldades na escola foi incluir diferentes vozes que, participando do processo, silenciadas, corroborariam para a simplificação da questão e a consequente minimização da participação subjetiva. O estudo de casos enquanto estratégia de pesquisa favoreceria esse recorte mais cuidadoso, em que seriam discutidos os múltiplos fatores em que intervém bem como seus diferentes agentes. Dito isso, a questão de nossa pesquisa pode ser enunciada da seguinte forma: como compreender o mal-estar na escolarização de crianças e adolescentes a partir das queixas de dificuldade de aprendizagem e agitação? Como pensar a participação dos diferentes atores nesse mal-estar (criança/adolescente, escola, família, especialistas)?

Para tentar responder a esses questionamentos, a pesquisa precisou ouvir, ler e interagir com as crianças e os adolescentes, família, especialistas e escolas. Dois anos foram dedicados à "coleta" e construção de material. Reunião com as famílias, entrevistas individuais com as crianças e os adolescentes, visitas às escolas, reuniões com especialistas, enfim, uma série de estratégias foram utilizadas. Não houve um desenho apriorístico das ações-intervenções que se constituíram a partir de cada caso, das demandas que cada um apresentava. Nesse sentido, em nossa pesquisa buscamos múltiplas fontes de evidência, sendo as principais: documentos, transcrições de reuniões de grupo, transcrições de entrevistas, relatórios de observação participante. Em relação a documentos, inserem-se aí registros nos livros de triagem, prontuários, relatórios da escola, relatórios de diagnósticos psicopedagógicos, fonoaudiológicos, psicodiagnósticos, diários das observações na escola, entre outros que o caso apresentou. As entrevistas também seguiram os quatro eixos, portanto, realizadas na escola, com especialistas, a família e a própria criança/adolescente. A observação participante incluiu prioritariamente $\mathrm{a}$ ida dos pesquisadores à escola, mas também foi feita quando o usuário frequentou o serviço. Todas as reuniões com as famílias e quase todas as entrevistas foram gravadas, formando-se um banco de dados composto prioritariamente por relatórios e registros em áudio que foram transcritos. Documentaram-se todos os procedimentos (entrevistas, visitas, telefonemas, reuniões) concorrendo para a confiabilidade da pesquisa. Assim, a "utilização de várias fontes de evidências, de tal forma que incentive linhas convergentes de investigação" (Yin, 2005, p. 33), foi uma tática para aumentar a validade. Já que nosso objeto de estudo foi o discurso desses diferentes agentes quanto ao mal-estar, tudo que se referiu a ele foi, a princípio, de interesse. $\mathrm{O}$ dito, o não dito, enfim

a investigação de estudo de caso enfrenta uma situação tecnicamente única em que haverá muito mais variáveis de interesse do que pontos de dados, e, como resultado, baseia-se em várias fontes de evidências, com os dados precisando convergir em um formato de triângulo e, como outro resultado, beneficia-se do desenvolvimento prévio de proposições teóricas para conduzir a coleta e a análise de dados (Yin, 2005, p. 33).

Justamente o projeto de pesquisa constitui a lógica que une os dados a serem coletados (e as conclusões a serem tiradas) às questões iniciais de um estudo (Yin, 2005, p. 40). Portando, ao "coletar" e sistematizar os diferentes discursos estávamos não só discutindo os múltiplos fatores que intervém nas chamadas dificuldades de aprendizagem, como ampliando sua contextualização.

\section{Organização e análise do material}

Há, às vezes, uma confusão entre o estudo de caso como método de pesquisa e os casos como forma de 
manter registros, importantes para a prática, mas que não respondem às exigências do método. Na psicanálise, por exemplo, encontramos com frequência o uso de extratos clínicos, ou vinhetas clínicas (Nasio, 2001, p. 12) com função de exemplificar aspectos da teoria sem, contudo, se constituir num estudo de caso propriamente dito. Nesta pesquisa, diferentemente, tínhamos como objeto de pesquisa cinco crianças e adolescentes a acompanhar durante dois anos e todo o discurso referente ao malestar na escolarização a eles relacionado, um problema de pesquisa e um grande eixo analítico que consistia em, metodologicamente, compreendê-lo nos quatro diferentes discursos.

A fase de análise da pesquisa configurou-se como um de seus grandes desafios. Por um lado, a pesquisa tinha um design inicial apontando os quatro grandes eixos de análise que se mantiveram e orientaram o campo. No entanto, dentro de cada grande eixo analítico (família, escola, sujeito, especialista), o material produzido durante os dois anos de campo foi volumoso. O banco de dados muito extenso necessitou de várias organizações, tendo sido utilizados o Dropbox e o Google Drive como sistemas de arquivamento. Diante dessa quantidade de material, a análise dos pesquisadores se deu nos sentidos descritos a seguir. $\mathrm{O}$ a posteriori se configurou como um guia para o delineamento das categorias e subcategorias dentro de cada eixo. Ou seja, se aprioristicamente, no projeto, tínhamos a questão e os grandes eixos definidos, num terceiro momento da análise, debruçados sobre o material, as categorias e subcategorias foram construídas no só depois. Líamos todo o material mais de uma vez num grupo de dois coordenadores e cinco alunos de iniciação científica, e mapeávamos as recorrências e diferenças nos discursos, temáticas prevalentes. Após a leitura apontávamos algumas possíveis categorias e voltávamos ao material. Algumas se mantinham e outras eram descartadas, pois não contemplavam de forma suficiente os discursos. As mantidas eram aprimoradas e geravam subcategorias. Aqui, um ponto muito importante foi a teoria e a experiência clínica das pesquisadoras.

Por exemplo, ao efetivar a análise do eixo família, o grupo de pesquisa, num momento inicial, se debruçava ao estudo do estado da arte das pesquisas em psicanálise, educação e família. A partir desta pesquisa teórica apareciam tendências que, posteriormente, confrontadas com o material de campo, poderiam influenciar na construção das categorias ou não. $O$ fato de se utilizar do a posteriori na construção das categorias e subcategorias trouxe vantagens e desvantagens. A grande vantagem, que se coaduna ao fazer psicanalítico, é um certo esvaziamento do saber, ouvirmos o discurso pelo discurso, deixando-nos afetar por aquilo que ele traz de novo, de diferente, de inusitado. Aqui a postura do pesquisador clínico empresta aquilo que Freud (1912/1996a) chama de atenção flutuante, para que a voz do sujeito pesquisado se sobrepuje à do pesquisador. No entanto, ao desenharmos categorias no só depois, encontramos diferentes categorias em cada eixo, o que dificultou bastante a discussão comparativa entre elas. Por exemplo, no eixo família construímos duas grandes categorias a partir do mapeamento do mal-estar enunciado nas falas dos pais - escola examinadora e escola que não cumpre as expectativas, já no eixo escola, a partir do discurso dos educadores, outras duas-ideal de aluno e ideal de escola/professor.

De forma muito sintética e reduzida para fins deste artigo, podemos dizer que nos quatro eixos encontramos uma grande relação entre mal-estar e ideal. Frequentar uma escola envolve necessariamente ideais de aluno, de aprendizagem, de cidadão, de filho, enfim, matrizes muitas vezes silenciosas e silenciadas que atravessam a produção do mal-estar e podem passar facilmente desapercebidas tanto pela escola como pela saúde mental, pela família e pelo próprio sujeito. Por exemplo, numa análise longitudinal quanto à queixa inicial de dificuldade de aprendizagem por parte de adolescente da pesquisa, encaminhada pela escola, a partir da escuta da família, das visitas à escola e posterior análise do material, constatou-se que a visão de aprendizagem da família estava diretamente relacionada à suposta dificuldade da aluna, que tirava notas baixas como forma de visibilidade e resistência a um modelo inatingível. Num outro caso de um menino de sete anos que fazia uso de medicação controlada, também com queixa inicial de dificuldade de aprendizagem, foi possível constatar que, apesar dos discursos do especialista, da família e da escola afirmarem que tudo ia bem com a interferência medicamentosa, nas observações participantes na escola, a pesquisadora constatou que a criança dormia a metade do horário do turno escolar. Aqui, por exemplo, o ideal de criança quieta, favorecido pelo uso do remédio, poderia estar apaziguando o mal-estar na escola. Enfim, a análise do mal-estar foi bastante longa e gerou muitos aspectos de discussão, tanto interventivos quanto conceituais que excedem o objetivo deste escrito.

$\mathrm{Na}$ análise comparativa dos cinco casos, riquíssima em diferenças, o ponto de convergência entre ideal e mal-estar se manteve, mesmo que enunciado por formas bastante peculiares e singulares em cada caso.

\section{À guisa de resultados}

Mais uma vez, para fins deste artigo, sintetizaremos significativamente a discussão dos resultados. De modo geral, a hipótese inicial de que as queixas de agitação e dificuldade de aprendizagem, se consideradas como expressões de mal-estar, poderiam longitudinalmente ganhar um contorno bastante diverso do inicial se concretizou. Ou seja, antes de compreender como possível caracterização de um transtorno (quatro casos foram diagnosticados, ou tiveram a sugestão de TDAH), ao considerarmos a queixa apenas como indicação de um mal-estar somos necessariamente compelidos a tentar compreendê-lo a partir das relações estabelecidas. De quem 
é o mal-estar? Quem o enuncia? O que ele diz? De outro modo o "transtorno", fiduciário do modelo de doença e já previamente definido, predominantemente localiza no próprio sujeito, individualizando o "mal" e, não poucas vezes, o tomando como biológico (Guarido \& Voltolini, 2009; Costa, 2004). Então, num aspecto interventivo, a partir da análise do discurso principalmente no eixo família e escola, foi possível constatar certa "vantagem" para os atores envolvidos, sobretudo em três dos cinco casos, inferida a partir de falas como "melhorei", "agora consigo falar", "minha relação com ele melhorou", "estou olhando para ele de forma diferente", entre vários outros ditos. Nesse sentido, o estudo de casos como forma e subsídio para a intervenção na pesquisa se mostrou interessante porque possibilitou certo deslocamento dos participantes, incluindo nisso os próprios pesquisadores. Num sentido micropolítico, a estratégia de pesquisa, ao aprofundar os casos trouxe à tona a complexidade do singular em relação a uma queixa inicial mais difusa e generalizada, que poderia concorrer para a compreensão da agitação ou dificuldades no aprender como índices de patologias.

Num viés mais conceitual podemos dizer que, de posse das diversas análises, não podemos pensar em mal-estar na escola sem considerar o atravessamento dos diversos ideais nessa produção. O ideal, portanto, acabou se constituindo como conceito-chave para a compreensão do mal-estar, configurando-se na categoria prevalente entre os quatro eixos e na análise comparativa dos cinco casos.

A pesquisa gerou muitos produtos, como mais de dez trabalhos de iniciação científica, cinco artigos em revistas indexadas, dois capítulos de livro e várias apresentações em congressos. No atual momento, as coordenadoras estão produzindo um livro com os resultados gerais da pesquisa.

\section{Desafios metodológicos}

O estudo dos casos revelou que ter o mal-estar na escolarização como objeto é, fundamentalmente, perguntar quem o enuncia e em qual relação ele toma forma. Nesse aspecto, a estratégia de pesquisa é interessante porque pode acontecer no próprio contexto onde supostamente o mal-estar se produz. Num dos casos, por exemplo, as idas da pesquisadora à escola revelou que, apesar da queixa inicial, não havia nenhum educador que sustentasse no discurso apontamentos sobre mal-estar, pelo contrário, para eles tudo seguia dentro do esperado. A produção do mal-estar se concentrava no eixo da família, sobretudo naquilo que a família esperava da criança. Esse achado não foi sem impasses, pois acabamos não incluindo esse material na análise comparativa dos casos, que pressupunha certo envolvimento da escola, ainda que tenha ajudado a clarear a importância do contexto pesquisado no estudo de casos.

Também, ao realizar uma pesquisa em psicanálise fora do seu contexto estrito - a clínica-, deparamos com grandes desafios. O primeiro, a nosso ver, é em relação ao objeto da psicanálise, que é o inconsciente. Sem dúvida, um pesquisador guiado pela psicanálise necessariamente parte do paradigma do inconsciente. Esse ponto claro e incontestável, já que é uma premissa teórica, logo encontra dificuldades quando se pensa o campo estendido. Uma das razões pode ser assim traduzida: como pesquisar o inconsciente para além da clínica? Freud nos deixou claras matrizes de pesquisa clínica e apostou na relação entre psicanálise e educação, mas não avançou neste último campo. No contexto clínico, tratamento e pesquisa coincidem, e essa é uma máxima freudiana importante. No contexto educativo, muitas vezes, não podemos falar em tratamento propriamente dito, mas numa intervenção na realidade estudada. No contexto da clínica, a pesquisa é do inconsciente, e se faz a partir de suas formações, a saber: chiste, sintoma, sonho e ato falho (Freud, 1915/1996b). Ao ouvirmos os sujeitos na pesquisa e intervirmos, estamos partindo da premissa do inconsciente, mas não estamos necessariamente tendo suas formações como objeto específico de pesquisa. Ao efetuarmos, posteriormente, a análise do material, também não estaremos guiados predominantemente para as formações do inconsciente. A questão transferencial também é delicada, já que consideramos a transferência e a levamos em conta. No entanto muitas vezes ela não estará posta em todas as situações de pesquisa, sendo muito diferente sua participação na clínica.

Nesse sentido, fazer pesquisa em psicanálise, para além da clínica, nos convoca a permanentemente pensar essa relação, aprimorar critérios, articular saberes. Ao escolhermos o termo mal-estar como objeto, que não se trata de um conceito metapsicológico propriamente dito, sabíamos contar com certa plasticidade teórica, o que enriqueceu e ampliou a discussão. Por outro lado, na análise do material não foi simples a localização do mal-estar no discurso, já que muitas vezes as evidências eram sutis e contaram com a experiência clínica das duas pesquisadoras coordenadoras. Enfim, iniciamos este relato de pesquisa argumentando sobre a utilização da estratégia de estudos de casos múltiplos e como a fomos utilizando ao logo de mais de dois anos. Narramos sobre o desenho da pesquisa e os eixos principais de análise como pontos muito importantes, discutindo sinteticamente os resultados. Por fim, podemos dizer que as dificuldades não foram poucas, mas a articulação entre psicanálise e educação produziu efeitos interessantes nos aspectos interventivos e possibilitou ampliar crítica e reflexivamente a discussão que envolve a educação e a saúde mental. Entretanto, como o método é uma "atividade crítica da ciência, e não uma receita geral ou técnica de pesquisa" (Furlan, 2017, p. 83) há que se caminhar muito na discussão metodológica que envolve a articulação da psicanálise com os outros campos de saber, seus impasses e suas possibilidades. 


\section{Multiple cases studies: research strategy in psychoanalysis and education}

Abstract: The case study will be discussed as a research methodology for connecting psychoanalysis and education. This discussion is part of the study carried out by the partnership between the Interdisciplinary Center for Study and Research for Contemporary Childhood and Adolescence of the Federal University of Rio de Janeiro (NIPIAC-UFRJ), the Institute of Psychiatry (UFRJ), the School of Education of UFRJ, and the Fluminense Federal University (UFF), which analyzed cases of children and adolescents with difficulties in their schooling. By the topic of discontent in schooling, the association between case study and intervention research was useful to analyze contemporary phenomena inserted in real life contexts (Yin, 2005). We discuss the importance of case definition, of the question of study and production of material, its organization and analysis, as well as results and products. Finally, we carry out a reflection on the methodological challenges found in the research.

Keywords: case studies, research methodology, psychoanalysis, education.

\section{L'étude de cas multiples: stratégie de recherche en psychanalyse et éducation}

Resume: On debat ici les études de cas comme méthodologie de recherche sur la relation entre la psychanalyse et l'éducation. Cette discussion est incluse dans le travail en partenariat entre le Centre interdisciplinaire d'études et de recherche sur l'enfance et l'adolescence contemporaine et Université Fédérale de Rio de Janeiro (NIPIAC-UFRJ), I'Institut de Psychiatrie (UFRJ), I'École de l'éducation UFRJ et I'Universidade Federal Fluminense (UFF), où des cas des enfants et des adolescents avec des obstacles à l'éducation ont été analysées. Le thème du malaise dans l'enseignement, les études de cas associées à la recherche d'intervention, sont bien adaptées à l'analyse des phénomènes contemporains insérés dans des contextes de la vie réelle (Yin, 2005). On parle ici sur l'importance de la définition de cas, la problematique de l'étude et de la production du matériel, son organization, l'analyse ainsi que les résultats et les produits. Enfin, une réflexion c'est construite sur les défis méthodologiques rencontrés dans la mise en œuvre de la recherche.

Mots-clés: étude de cas, méthodologie de recherche, psychanalyse, l'éducation.

\section{El estudio de casos múltiples: estrategia de investigación en psicoanálisis y educación}

Resumen: Los estudios de casos serán discutidos como metodología de investigación sobre la relación entre el psicoanálisis y la educación. Esta discusión está dentro del trabajo realizado por la asociación entre el Centro Interdisciplinar de Estudios e Investigación de la Niñez y Adolescencia Contemporáneas de la Universidad Federal de Río de Janeiro (NIPIAC-UFRJ), del Instituto de Psiquiatría (UFRJ), la Escuela de Educación de la UFRJ y Universidad Federal Fluminense (UFF), donde se analizaron los casos de niños y adolescentes con barreras en la educación. A través del tema del malestar en la educación, los estudios de casos combinados con la metodologia de investigación se presentan propicios para el análisis de los fenómenos contemporáneos insertados en los contextos de la vida real (Yin, 2005). Aquí se argumenta sobre la importancia de la definición de caso, la cuestión del estudio y la producción de material, organización y análisis, así como los resultados y productos. Por último, se teje una reflexión sobre los retos metodológicos encontrados en la investigación.

Palabras clave: estudio de casos, metodología de investigación, psicoanálisis, educación.

\section{Referências}

Bauer, M., \& Gaskell, G. (2002). Pesquisa qualitativa com texto, imagem e som: um manual prático. Petrópolis, RJ: Vozes.

Bergés, J. (1999). A instância da letra na aprendizagem. Revista da APPOA (Associação Psicanalítica de Porto Alegre), 9(16), 137-146. Recuperado de https://bit.ly/2tnenDd

Carneiro, C., \& Coutinho, L. G. (2015). Infância e adolescência: como chegam as queixas escolares à saúde mental? Educar em Revista, 56, 181-192. doi: $10.1590 / 0104-4060.37764$
Carneiro, C., \& Coutinho, L. G. (2016). Infância, adolescência e mal-estar na escolarização: interlocuções entre a psicanálise e a educação. Psicologia Clínica, 28, 109-129.

Castro, L. R., \& Besset, V. (Orgs.). (2008). Pesquisa-intervenção na infância e juventude. Rio de Janeiro, RJ: Nau Editora.

Catharino, T. (2001). Psicologia na educação: contribuições da análise institucional para o processo pedagógico. In I. Maciel (Org.), Psicologia e educação: novos caminhos para a formação (pp. 35-54). Rio de Janeiro, RJ: Ciência Moderna. 
Colli, F. A. G., \& Kupfer, M. C. (2005). Travessias: a experiência do Grupo Ponte - Pré-escola terapêutica lugar de vida. São Paulo, SP: Casa do Psicólogo.

Costa, J. F. (2004). Ordem médica e norma familiar. Rio de Janeiro, SP: Graal.

Freud, S. (1996a). Recomendações aos médicos que exercem psicanálise. In Edição standard brasileira das obras psicológicas completas de Sigmund Freud (J. Salomão, trad. Vol. 12, pp. 123-133). Rio de Janeiro, RJ: Imago. (Trabalho original publicado em 1912)

Freud, S. (1996b). O inconsciente. In Edição standard brasileira das obras psicológicas completas de Sigmund Freud (J. Salomão, trad. Vol. 14, pp. 163-222). Rio de Janeiro, RJ: Imago. (Trabalho original publicado em 1915).

Freud, S. (1996c). O futuro de uma ilusão. In Edição standard brasileira das obras psicológicas completas de Sigmund Freud (J. Salomão, trad. Vol. 21, pp. 15-63). Rio de Janeiro, RJ: Imago. (Trabalho original publicado em 1927)

Freud, S. (1996d). O mal-estar na civilização. In Edição standard brasileira das obras psicológicas completas de Sigmund Freud (J. Salomão, trad. Vol. 21, pp. 67-150). Rio de Janeiro, RJ: Imago. (Trabalho original publicado em 1930)

Furlan, R. (2017). Reflexões sobre o método nas ciências humanas: quantitativo ou qualitativo, teorias e ideologias. Psicologia USP, 28(1), 83-89. doi: 10.1590/0103656420150134

Guarido, R., \& Voltolini, R. (2009). O que não tem remédio, remediado está? Educação em Revista, 25(1), 239-263. doi: 10.1590/S0102-46982009000100014
Jerusalinsky, A. (1999). O outro do pedagogo. Ou seja, a importância do trauma na Educação. Revista da APPOA, 9(16), 7-13. Recuperado de https://bit.ly/2tnenDd

Lajonquière, L. (2010). Figuras do infantil: a psicanálise na vida cotidiana com as crianças. Petrópolis, RJ: Vozes.

Mannoni, M. (1999). A criança, sua "doença” e os outros. São Paulo, SP: Via Lettera.

Millot, C. (2001). Freud antipedagogo. Rio de Janeiro, RJ: Zahar.

Nasio, J. D. (2001). Os grandes casos de psicose. Rio de Janeiro, RJ: Jorge Zahar.

Paín, S. (1985). Diagnóstico e tratamento dos problemas de aprendizagem. Porto Alegre, RS: Artes Médicas.

Santiago, A. L. (2005). A inibição intelectual na psicanálise. Rio de Janeiro, RJ: Jorge Zahar.

Ventura, M. M. (2007). O estudo de caso como modalidade de pesquisa. Revista Socerj, 20(5), 383-386. Recuperado de https://bit.ly/2M6uKM6

Verztman, J. S. (2013). Estudo psicanalítico de casos clínicos múltiplos. In A. M. Nicolaci-da-Costa, \& D. R. Romão-Dias (Orgs.). Qualidade faz diferença: métodos qualitativos para a pesquisa em psicologia e áreas afins (pp. 67-92). Rio de Janeiro, RJ: Loyola.

Yin, R. K. (2005). Estudo de caso: planejamento e métodos. Porto Alegre, RS: Bookman. 